\title{
Türkiye'de Çevre ve Ekonomik Büyüme Arasındaki İlişki: ARDL Sınır Testi Yaklaşımı
}

\section{The Relationship Between Environment and Economic Growth in Turkey: An ARDL Bounds Testing Approach}

\author{
Prof. Dr. Ramazan Kılıç - Arş. Grv. Güray Akalın
}

\section{Öz}

Bu çalışmanin amacl; ekonomik büyüme ile çevre arasindaki ilişkiyi incelemektir. Bu amaçla, Çevresel Kuznets Eğrisi hipotezinin (ÇKE) 1960-2011 dönemi için Türkiyede geçerliliği test edilmiştir. Ekonomik büyüme göstergesi olarak Kişi Başına Düşen Milli Gelir, çevre kirliliği göstergesi olarak da Kişi Başına Karbondioksit (CO2) emisyonu kullanılmıştır. Ayrıca kontrol değişkeni olarak da ticari dışa açıklık oranı modele dahil edilmiştir. ARDL (The Autoregressive Distributed Lag) modeli ile elde edilen bulgular şöyle stralanabilir: i) Kuadratik model için elde edilen uzun dönemli katsayılara göre, kişi başına gelir ile çevre kirliliği arasında ters $U$ şeklinde bir ilişkinin mevcut olduğu görülmektedir. Bu sonuç ÇKE hipotezinin 1960-2011 döneminde Türkiye'de geçerli olduğunu desteklemektedir. ii) Kubik model için elde edilen uzun dönemli katsaynlara göre, gelir ile çevre kirliliği arasında $N$ şseklinde bir ilişki mevcuttur.

Anahtar Kelimeler: Çevresel Kuznets Ĕ̆risi (ÇKE), CO2 Emisyonu, Ekonomik Büyüme, ARDL Sinır Testi

\begin{abstract}
The main purpose of this study is to examine the interaction between economic growth and the environment. To this end, Environmental Kuznets Curve (EKC) hypothesis has been tested in Turkey for 19602011 period. The National Income Per Capita as an indicator of economic growth, Per Capita Carbon Dioxide (CO2) emissions as an indicator of environmental pollution has been used. Also trade openess rate has been included in the model as a control variable. The
\end{abstract}

results which obtained by ARDL (The Autoregressive Distributed Lag) model can be listed as follows: i) According to the long-term coefficients which obtained for quadratic model; there is an inverted $U$ shaped relationship between per capita income and environmental pollution. These results support validity of EKC hypothesis for 1960-2011 in Turkey. ii) According to the longterm coefficients which obtained for cubic model; there is an $N$ shaped relationship between per capita income and environmental pollution.

Keywords: Environmental Kuznets Curve (EKC), CO2 Emissions, Economic Growth, ARDL Bound Test

\section{Giriş}

Ekonomik faaliyetlerin temel amacı insanların refah düzeyini artırmaktır. Refah artışı ise genellikle toplumların tüketim düzeyinde ortaya çıkan artış olarak açıklanabilir. Neo-klasik iktisadın empoze ettiği tüketim-fayda ve kar-maliyet ilişkisi tartışmaya açı olsa da genel olarak kabul gören bir teoridir. Bu bağlamda tüketim ne kadar artarsa, toplumların faydalarının da artacağ düşüncesiyle üretim artışı neredeyse ekonomilerin birincil hedefi haline gelmiştir. Bu anlayışın ortaya çıkardığ 1 en büyük problem ise, yaşanan çevresel sorunlardır. Üretim için kaynak kullanımı arttığında bir yandan üretim faktörleri azalırken bir yandan da üretim ve tüketim sonrası oluşan atıklar çevresel maliyeti artırmaktadır. Bunun sonucunda da birçok çevresel sorun ortaya çıkmaktadır. Çevrenin iktisat bilimi için önemi büyüktür. Ancak; çevre sorunları ve çevrenin kirlenmemesi için iktisat bilimi

Prof. Dr. Ramazan Kılıç, Dumlupınar Üniversitesi İ̈BF, ramazan.kilic@dpu.edu.tr Arş. Grv. Güray Akalın, Dumlupınar Üniversitesi İIBF, guray.akalin@dpu.edu.tr 
içerisinde çözüm arayışı uzun yıllar ihmal edilmiştir. Bunun sonucunda da günümüzde çevresel sorunlar giderek artmıştır (Erdem ve Ulucak, 2012, s.80-81). Çevresel sorunları şu şekilde sıralamak mümkündür: İklim değişikliği ve küresel ısınma, hava kirliliği, su kirliliği, toprak kirliliği, biyolojik çeşitliliğin azalması ve orman tahribatı. Günümüzde çevre sorunlardaki artışların ciddi boyutlara ulaşması ile birlikte bu sorunun ancak küresel çabalarla çözümlenebileceğini ortaya koymuştur. Bu amaçla, global ölçekli işbirlikleri oluşturulmaya ve organizasyonlar düzenlenmeye başlanmıştır. İlk olarak 1972'de düzenlenen Stockholm Konferansı ile birlikte çevresel sorunların dünyanın ortak sorunu olduğu kabul edilmiştir. Çevre sorunlarının artması ile birlikte çevre-ekonomik büyüme ilişkisi tartışmaları yoğun olarak yapılmıştır. $\mathrm{Bu}$ amaçla, ekonomik büyümenin yarattığı çevre baskısını veya çevre kalitesi üzerindeki etkisini ölçmeyi amaçlayan ve bunu temsilen çeşitli kirlilik yaratıcı değişkenleri kullanan birçok ampirik çalışma yapılmıştır (Tutulmaz, 2011, s.64-65). Bunun yanında çevresel sorunların çözümüne yönelik düzenlemelerin ise ek maliyetler yolu ile ekonomik büyüme üzerinde baskı kuracağına yönelik çalışmaların sayısı da giderek artmaktadır. Çevreyi dikkate alarak gerçekleştirilen üretim faaliyetlerinin ek maliyetler yaratacağ rım maliyetlerinin artacağ 1 tahmin edilmektedir. $\mathrm{Bu}$ ilave maliyetlerin ise ekonomik aktiviteleri daraltacağı öngörülmektedir (Çiftlikli, 2011, s.47-48). Bu ampirik çalışmaların iktisat literatüründe Çevresel Kuznet Eğrisi (ÇKE) etrafında toplandığı görülmektedir. Bunun temel nedeni ise modelin ekonomik büyüme ve çevresel göstergeler arasındaki ilişkiyi basit ve ekonometrik olarak ortaya koyabilmesi, bunu yaparken de 1960'lardan beri çeşitli uluslararası ve uluslar kuruluşlarca düzenli olarak ölçülen temel değişkenleri kullanıyor olmasıdır (Tutulmaz, 2011, s.64-65). Bu bağlamda bu çalışmanın amacı, Çevresel Kuznets Eğrisi Hipotezinin 1960-2011 dönemi için Türkiye'de geçerliliğini test etmektir. Bu çalışmanın planı ise şu şekildedir; ilk üç bölümde sırasıyla çalışmaya yön veren teorik altyapı ve literatür taraması verilmiştir. Dördüncü bölümde çalışmada kullanılan veri seti ve model hakkında bilgi verilmektedir. Beşinci bölümde metod ve bulgular sunulmuştur. Son bölümde ise; ekonometrik analizlerde elde edilen sonuçlar Türkiye’ye özgü durumlar göz önünde bulundurularak yorumlanmıştır.

\section{Çevresel Kuznets Eğrisi Hipotezi}

Kuznets (1955), ekonomik büyüme ile gelir dağılımı arasındaki ilişkiye dair çalışmasında, ekonomik gelişmenin ilk aşamalarında gelir eşitsizliğinin artığ 1 , fakat belli bir gelişme düzeyinden sonra gelir eşitsizliğinde azalma ortaya çıktığını göstermiştir. Grossman ve Krueger (1991) ise; Kuznets eğrisini çevre kirliliği ve ekonomik büyüme arasındaki ilişkiyi incelemeye yönelik uyarlayarak, gelir artışıla çevre kirliliğinin artmakta olduğunu belirli bir eşik düzeyinden sonra çevre kirliliğinin azaldığı sonucunu bulmuşlardır. Şekil 1'de gösterilen bu çan eğrisi ilişkisi Çevresel Kuznet Eğrisi olarak adlandırılmaktadır. Genellikle iktisatçılar ÇKE hipotezinin arkasında yatan mekanizmaların, başka bir ifade ile kişi başına gelir düzeyi ile çevre kirlenmesi ilişkisinin neden ters U biçiminde bir seyir izlediğini teorik düzeyde açıklarken üç faktörün etkili olduğunu ifade etmektedirler (Saatçi ve Dumrul, 2012, s.66-67). Bu faktörler ölçek etkisi, yapısal etki ve teknoloji etkisidir (Grossman ve Krueger 1991, s.1-2). Ölçek etkisine göre, üretim arttıkça üretim sürecinde kullanılan bir girdi olarak daha fazla doğal kaynak kullanılmaktadır. Üretim sürecinde daha fazla doğal kaynak kullanılması, teknoloji veri iken doğanın tahrip olmasına ya da çevre bozulmalarına neden olmaktadır (Başar ve Temurlenk, 2007, s.2-3). Yapısal etkiye göre, ülkelerin gelirlerinin artması ile birlikte ekonominin yapısı değişmekte, tarımdan sanayiye, sanayiden de bilgi ve hizmet sektörüne geçiş yaşanmaktadır (Başar ve Temurlenk, 2007, s.2-3). Gelir artışı ile birlikte artan temiz çevreye talep oluşturduğu toplumsal baskılar yoluyla çevresel kamu harcamalarının artışını içeren katı çevre politikalarını gündeme getirecektir. Katı çevre politikaları firmaların üretim maliyetlerini arttırıp uluslararası piyasada rekabet güçlerini düşüreceğinden, söz konusu firmalar rekabet güçlerini koruyabilmek için üretimlerini gevşek çevre politikaları olan ülkelere doğrudan yabancı yatırımlar yoluyla kaydıracaklardır. (Şahinöz ve Fotourehchi, 2013, s.202-203). Teknoloji etkisine göre, ülkelerin refah düzeylerinin artması ile birlikte araştırma ve geliştirme çalışmaları için ayrılan fonlarda da artışlar kaydedilmektedir. Teknolojik gelişmeler sonucunda elde edilen yeni ve çevre dostu teknolojilerin kullanılması ile birlikte çevre kalitesinde iyileşme görülmekte ve verimlilik artışları sağlanmaktadır (Saatçi ve Dumrul, 2012, s.67-68). 


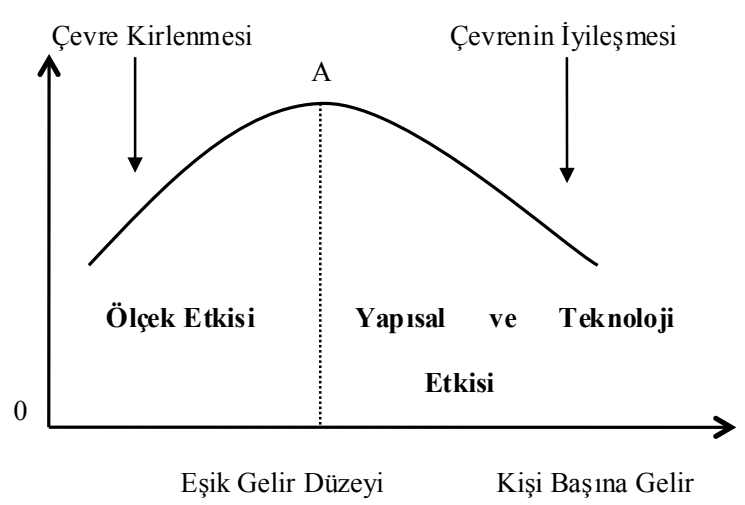

Şekil 1. Çevresel Kuznets Eğrisi ve Açıllayııı Faktörler

ÇKE ilişkisinin açıklanmasına yönelik bir diğer yaklaşım ise; kaliteli çevreye olan talebin gelir esnekliğidir. $\mathrm{Bu}$ bağlamda üretiminde ya da tüketiminde çevre kirliliğine yol açan bir mal gelirin düşük düzeylerinde normal bir mal olarak değerlendirilmektedir. Gelir artışı ile birlikte çevreyi kirleten bu mallar düşük mal haline dönecek ve bu mallara talep azalacaktır. Başka bir ifade ile Neo-klasik iktisat yaklaşımında, çevresel kalitedeki gelişimin iktisadi büyüme ile birlikte gerçekleşebileceği argümanının temel dayanağı kişi başına gelirin artacak olmasıdır. Artan kiși başına gelir, lüks mallara olan kaliteli çevre talebini arttıracaktır. Çevrenin iyileşmesi için daha çok harcama yapılması sayesinde büyüme, çevre için olumlu etkide bulunmuş olacaktır (Aslan, 2010, s.71-72). Martin Lieb (2002) çalışmasında gelir artışı ile eğitimin artacağı ve bunun da çevre konusunda farkındalık yaratacağını belirtmiştir. Ayrıca, gelir artışı ile birlikte gelir dağılımın düzeleceği ve çevreye olumlu yansıyacağı, dışsal etkilerin içselleştirilmesinden sonra uygulanan politikalar, kirleticiler arasındaki ikame ve son olarak ta enerji sektöründe yaşanan krizlerin ÇKE’sinin şeklini ve dönüm noktalarını etkilediğini ileri sürmüștür (Martin Lieb, 2002, s.40-41).

ÇKE modeli uygulamalarıla, ekonomik büyüme ve çevre kirliliği arasındaki ilişkisinin türü tartışılmaktadır. Bu ilişki türünün ortaya çıkarılması, ekonomiyi temsilen açıklayıcı değişken olarak modelin sağ tarafında yer verilen gelir değişkenin farklı biçimleri ile sağlanmaktadır (Tutulmaz, 2011, s.69-70). Pek çok ampirik araştırma, ÇKE'yi kuadratik veya kübik denklem ile göstermektedir. Denklem çeşitli hava kirliliği endeksi ile kişi basına gelir ilişkisini incelemektedir. Temel indirgenmiş (income-reduced) form ÇKE modeli ve yorumlanması Bruyn ve Heintz tarafından şu şekilde özetlenmektedir.

\section{$E i t=\beta 0+\beta 1 Y i t+\beta 2 Y^{2} i t 2+\beta 3 Y^{3} i t 3+\beta 4 Z i t+e i t$}

Burada, E, çevre baskısı veya çevre kirliliği; Y, ekonomik gelişme temsilcisi;

$Z$, diğer değişkenler; i ve t: ülke ve zaman indeksi; e ise hata terimidir. Model, çevre ekonomi ilişkisine yönelik farklı biçimleri test etme olanağı vermektedir.

$\beta 1>0$ ve $\beta 2=\beta 3=0$ durumunda, eğri artan doğrusal ilişki göstermektedir.

$\beta 1<0$ ve $\beta 2=\beta 3=0$ durumunda, eğri azalan doğrusal ilişki göstermektedir.

$\beta 1>0 \beta 2<0$ ve $\beta 3=0$ durumunda, eğri kuadratik bir ters-U ilişkisi göstermektedir. Bu durumda bir dönüm noktası elde edilecek ve bu formülle hesaplana-

bilecektir: $Y=-\frac{\beta 1}{2 \beta 2} \quad$ olacaktır.

$\beta 1<0 \quad \beta 2>0 \quad \beta 3<0$ durumunda kübik polinomik ters $\mathrm{N}$ şeklinde bir ilişkiyi göstermektedir. Bu durumda 2 dönüm noktası elde edilecektir. Kübik denklemin özelliklerine göre, dönüm noktaları mevcutsa; dönüm noktaları

$$
Y_{1}=\frac{-\beta 2-\sqrt{\beta 2^{2}-3 \beta 1 \beta 3}}{3 \beta 3} \mathrm{ve}_{2}=\frac{-\beta 2+\sqrt{\beta 2^{2}-3 \beta 1 \beta 3}}{3 \beta 3}
$$

formülleriyle hesaplanabilmektedir. Ancak, dönüm noktaları yoksa, bulunan eğri, sürekli artan bir ilişkinin trendini gösterebilmektedir

$\beta 1>0 \quad \beta 2<0$ ve $\beta 3>0$ durumunda ise, N-tipli kübik polinominal bir ilişki görülmektedir. Bu durumda 2 dönüm noktası elde edilecektir. Kübik denklemin özelliklerine göre, dönüm noktaları mevcutsa; dönüm noktaları

$$
Y_{1}=\frac{-\beta 2-\sqrt{\beta 2^{2}-3 \beta 1 \beta 3}}{3 \beta 3} \text { ve } Y_{2}=\frac{-\beta 2+\sqrt{\beta 2^{2}-3 \beta 1 \beta 3}}{3 \beta 3}
$$


formülleriyle hesaplanabilmektedir. Ancak, dönüm noktaları yoksa, bulunan eğri, sürekli artan bir ilişkinin trendini gösterebilmektedir (Şahinöz ve Fotourehchi, 2013, s. 206-207; Aslan, 2010, s. 69-70).

\section{Literatür Taraması}

Çevre ve ekonomik büyüme ilişkisi üzerine yapılan çalışmalar, 1990 yıllarında çevresel sorunların ciddi seviyelere ulaşması ile birlikte başlamış ve ÇKE hipo- tezinin test edilmesine yönelik olarak yapılmıştır. $\mathrm{Bu}$ çalışmalarda, farklı model, yöntem, veri seti ve değişkenler kullanılmıştır. ÇKE hipotezini test etmeye yönelik çalışmalardan oluşan literatür incelendiğinde henüz bir uzlaşmanın var olmadığı söylenebilir.

\section{Model ve Veri seti}

Çalışmada, ekonomik büyüme ve çevre ilişkisine yönelik ampirik uygulama, Çevresel Kuznet Eğrisinin

Tablo 1. ÇKE Hipotezine Yönelik Ampirik Çalışmalar

\begin{tabular}{|c|c|c|c|c|c|}
\hline Yazar & $\begin{array}{l}\text { Orneklem } \\
\text { ve Dönem }\end{array}$ & Yöntem & $\begin{array}{l}\text { Bağımlı } \\
\text { Değiskken }\end{array}$ & Bağımsız Değişken & Sonuç \\
\hline $\begin{array}{l}\text { Akbostanc1, } \\
\text { Türüt-Aşık ve } \\
\text { Tunç (2009) }\end{array}$ & $\begin{array}{l}\text { Türkiye } \\
1968-2003\end{array}$ & $\begin{array}{l}\text { Zaman Serisi } \\
\text { Analizi } \\
\text { (Kubik Form) }\end{array}$ & 1) $\mathrm{CO}_{2}$ & Kişi Başına GSYİH & $\begin{array}{l}\text { 1) ÇKE geçerli } \\
\text { değil. } \\
\text { N Şeklinde bir ilişki } \\
\text { ortaya çkmıștır. }\end{array}$ \\
\hline $\begin{array}{l}\text { Başar ve } \\
\text { Tumerlenk } \\
\text { (2007) }\end{array}$ & $\begin{array}{l}\text { Türkiye } \\
1950-2000\end{array}$ & $\begin{array}{l}\text { Zaman Serisi } \\
\text { Analizi } \\
\text { (Kubik Form) }\end{array}$ & 1) $\mathrm{CO}_{2}$ & Kişi Başına GSYİH & $\begin{array}{l}\text { 1) ÇKE geçerli } \\
\text { değil. } \\
\mathrm{N} \text { Şeklinde bir ilişki } \\
\text { ortaya čkmıstır }\end{array}$ \\
\hline $\begin{array}{l}\text { At1c1 ve Kurt } \\
(2007)\end{array}$ & $\begin{array}{l}\text { Türkiye } \\
1968-2000\end{array}$ & $\begin{array}{l}\text { Zaman Serisi } \\
\text { Analizi } \\
\text { (Kuadratik } \\
\text { Form) }\end{array}$ & 1) $\mathrm{CO}_{2}$ & $\begin{array}{l}\text { 1) Kişi Başına GSYİH } \\
\text { 2) Toplam Ticaret } \\
\text { Açıklık İndeksi } \\
\text { 3) Tarımsal Ticaret } \\
\text { Açıklık indeksi }\end{array}$ & $\begin{array}{l}\text { 1) ÇKE geçerli (Ters } \\
\text { U) }\end{array}$ \\
\hline Soytaş ve Sarı & $\begin{array}{l}\text { Türkiye } \\
1960-2000\end{array}$ & $\begin{array}{l}\text { Zaman Serisi } \\
\text { Analizi }\end{array}$ & 1) $\mathrm{CO}_{2}$ & $\begin{array}{l}\text { Kişi Başına Enerji } \\
\text { Tüketimi, } \\
\text { Kişi Başına GSYİH }\end{array}$ & $\begin{array}{l}\text { 1) ÇKE geçerli } \\
\text { değil. }\end{array}$ \\
\hline $\begin{array}{l}\text { Acaravc1 ve } \\
\text { Öztürk } \\
(2010)\end{array}$ & $\begin{array}{l}\text { Türkiye } \\
1968-2005\end{array}$ & $\begin{array}{l}\text { Zaman Serisi } \\
\text { Analizi }\end{array}$ & 1) $\mathrm{CO}_{2}$ & $\begin{array}{l}\text { Kişi Başına GSYİH, } \\
\text { Enerji Tüketimi ve } \\
\text { İstihdam Oranı }\end{array}$ & $\begin{array}{l}\text { 1) ÇKE geçerli } \\
\text { değil. }\end{array}$ \\
\hline $\begin{array}{l}\text { Aslan } \\
(2010)\end{array}$ & $\begin{array}{l}\text { Türkiye } \\
1968-2005\end{array}$ & $\begin{array}{l}\text { Zaman Serisi } \\
\text { Analizi } \\
\text { (Kubik Form) }\end{array}$ & 1) $\mathrm{CO}_{2}$ & $\begin{array}{l}\text { Kişi Başına GSYİH ve } \\
\text { Nüfus Yoğunluğu }\end{array}$ & $\begin{array}{l}\text { 1) ÇKE geçerli } \\
\text { değil. N Şeklinde bir } \\
\text { ilişki ortaya } \\
\text { çkmıştır }\end{array}$ \\
\hline $\begin{array}{l}\text { Dam vd. } \\
\text { (2013) }\end{array}$ & $\begin{array}{l}\text { Türkiye } \\
1960-2010\end{array}$ & $\begin{array}{l}\text { Zaman Serisi } \\
\text { Analizi } \\
\text { (Kubik Form }\end{array}$ & 1) $\mathrm{CO}_{2}$ & $\begin{array}{l}\text { Kişi Başına GSYİH ve } \\
\text { Enerji Tüketimi }\end{array}$ & $\begin{array}{l}\text { 1) ÇKE geçerli } \\
\text { değil. N Şeklinde bir } \\
\text { ilişki ortaya } \\
\text { çımıștır }\end{array}$ \\
\hline $\begin{array}{l}\text { Koçak } \\
(2014)\end{array}$ & $\begin{array}{l}\text { Türkiye } \\
1960-2010\end{array}$ & $\begin{array}{l}\text { Zaman Serisi } \\
\text { Analizi } \\
\text { (Kubik Form) }\end{array}$ & 1) $\mathrm{CO}_{2}$ & $\begin{array}{l}\text { Kişi Başına GSYİH ve } \\
\text { Enerji Tüketimi }\end{array}$ & $\begin{array}{l}\text { 1) ÇKE geçerli } \\
\text { değil. N Şeklinde bir } \\
\text { ilişki ortaya } \\
\text { cıkmıștır }\end{array}$ \\
\hline $\begin{array}{l}\text { Erdoğan vd. } \\
(2015)\end{array}$ & $\begin{array}{l}\text { Türkiye } \\
1975-2010\end{array}$ & $\begin{array}{l}\text { Zaman Serisi } \\
\text { Analizi } \\
\text { (Kubik Form) }\end{array}$ & 1) $\mathrm{CO}_{2}$ & $\begin{array}{l}\text { Satın Alma Gücü } \\
\text { Paritesine Göre Kişi } \\
\text { Başına Düşen Gelir }\end{array}$ & $\begin{array}{l}\text { 1) ÇKE geçerli } \\
\text { değil. }\end{array}$ \\
\hline $\begin{array}{l}\text { Bölük ve Mert } \\
(2015)\end{array}$ & $\begin{array}{l}\text { Tü1kiye } \\
\text { 1961-2010 }\end{array}$ & $\begin{array}{l}\text { Zaman Serisi } \\
\text { Analizi } \\
\text { (Kuadratik } \\
\text { Form) }\end{array}$ & 1) $\mathrm{CO}_{2}$ & $\begin{array}{l}\text { Kişi Başına GSYIH ve } \\
\text { Yenilenebilir Enerji } \\
\text { Üretimi }\end{array}$ & $\begin{array}{l}\text { 1) ÇKE geçerli (Ters } \\
\text { U) }\end{array}$ \\
\hline
\end{tabular}


1960-2011 dönemi için Türkiye'de geçerliliğini sınamaya yönelik olacaktır. Çalışmada kullanılacak model aşağıdaki gibi kuadratik ve kubik model şeklinde olacaktır:

$$
\begin{aligned}
& C O_{2 i t}=\beta_{0^{+}} \beta_{1} G D P_{i t}+\beta_{2} G D P_{i t}^{2}+\beta_{3} T R_{i t}+\mathcal{E}_{i t} \\
& C O_{2 i t}=\beta_{0^{+}} \beta_{1} G D P_{i t}+\beta_{2} G D P_{i t}^{2}+\beta_{3} G D P_{i t}^{3}+\beta_{4} T R_{i t}+\varepsilon_{i t}
\end{aligned}
$$

Modelde çevresel gösterge olarak; iklim değişikliği ve enerji gibi ana meseleler ile doğrudan ilişkili olan ve çevreyi temsilinde hemfikir olunan $\mathrm{CO}_{2}$ (measured in metric kilograms per capita) salınımı kullanılmıştır. Ekonomik büyümeyi temsilen çalışmaların neredeyse tamamında kullanılan, kişi başına düşen reel GSYİH (per capita gdp-constant 2005 US\$) değişkeni kullanılmıştır. Son olarak, modelin ekonometrik yapısını iyileştirmeye yönelik kontrol değişkeni olarak ticari açılılı oranı (trade opennes rate, \% of GDP) kullanılmıştır. Modelde serilerin logaritmik düzeyleri kullanılmış olup tüm veriler Dünya Bankası Kalkınma Göstergelerinden (World Bank, 2015) alınmıştır. Modelde kullanılan değiş̧kenlerin serilerine ilişkin grafikler aşağıda gösterilmektedir.
LNCO2

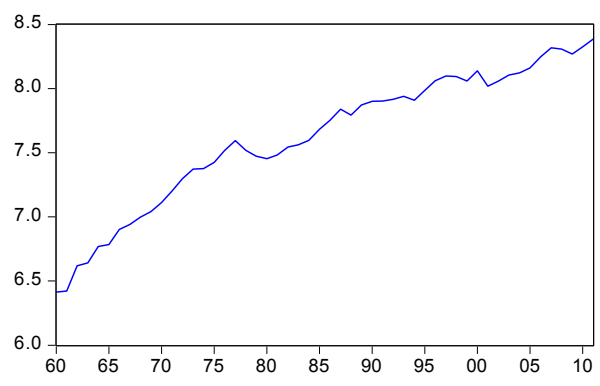

LNGDP2

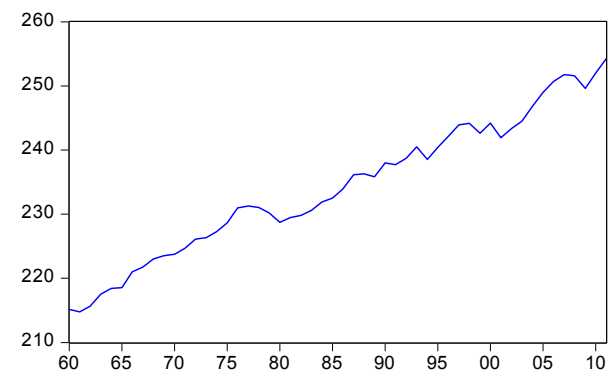

LNGDP

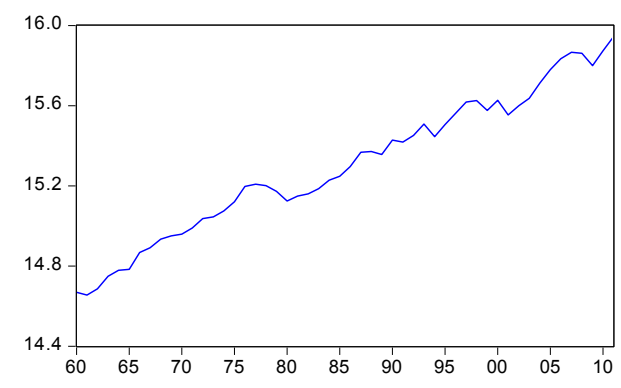

LNGDP3



LNTRD

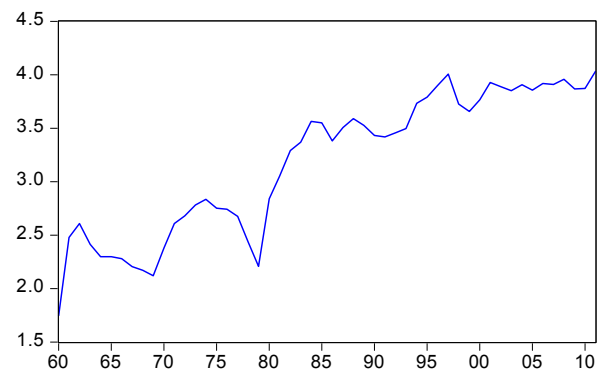

Şekil 2. Veri Setinin Konvensiyonel Analizi 
Şekil 2 incelendiğinde Türkiye için ilgili dönemde emisyonların sürekli artan bir eğilim gösterdiği görülmektedir. Diğer taraftan kişi başına milli gelir grafiğine bakıldığında sık aralıklarla geriye dönüşler gösterse de o da sürekli artan bir eğilim göstermektedir. Ticari açıklık serisi ise ciddi kırılmalara sahip olmakla birlikte onun da sürekli artan bir eğilim gösterdiğini söylemek mümkündür.

\section{Metod ve Bulgular}

$\mathrm{Bu}$ çalışmada öncelikle verilerin hangi dereceden bütünleşik olduğunu anlamaya yönelik Dickey ve Fuller (1981) tarafından geliştirilen ADF (Augmented Dickey-Fuller) ve Phillips ve Perron (1988) tarafından geliştirilen PP birim kök testleri kullanılacaktır. Serilerin aynı dereceden eş bütünleşik [I(1)] ya da bazılarının $[\mathrm{I}(0)]$ olması durumunda seriler arasinda uzun dönemli bir ilişki olup olmadığı Pesaran (1997), Pesaran vd. $(2000,2001)$ tarafindan geliştirilen ARDL (The Autoregressive Distributed Lag) modeli ile araştırılacaktır. Söz konusu değişkenler arasında eş bütünleşme ilişkisinin varlığı halinde, takip eden aşamalarda ise ÇKE modeline ilişkin hata düzeltme modeli tahmin edilerek kısa dönem dengesizliğin uzun dönemde düzeltilip düzeltilemediği incelenecektir.

\section{Autoregressive Distributed Lag (ARDL) Eşbütünleşme Analizi}

Çalışmanın bu aşamasında serilerin uyum derecesinin [I(1)] olduğundan hareketle eș bütünleşme araştırması yapılacaktır. Yukarıda değinildiği gibi değişkenler arasındaki uzun dönemli ilişki Pesaran (1997), Pesaran vd. $(2000,2001)$ tarafından geliştirilen ARDL (The Autoregressive Distributed Lag) modeli ile araştırılacaktır. Bu yaklaşım Engle ve Granger (1987), Johansen (1988) ve Johansen ve Juselius (1990) gibi diğer eş bütünleşme testlerine göre bir çok avantaja sahiptir. Bunlardan bazılarını şöyle sıralamak mümkündür: i) Bu test serilerin tamamının [I(0)], [I(1)] ya da bazılarının [I(0)] bazıların [I(1)]'inci dereceden bütünleşik olmaları durumunda değişkenler arasında eş bütünleşme ilişkisinin var olup olmadığını araştırmaktadır. Ancak; serileri [I(2)] olması durumunda bu test kullanilamaz. ii) Bu test kullanılan örneklemin küçük ya da bazı açıklayıcı değişkenlerin içsel olması durumunda bile etkili bir tahmincidir. iii) Sınır testi prosedürü Johansen ve Juselius (1990) eş bütünleşme tekniklerinden farklı olarak, birim kök testi modeline dahil edilen değișkenlerin ön testlerinin yapılmasını gerektirmemektedir. iiii) Son olarak, sinır testi ile modelin kısa ve uzun dönem parametreleri eşanlı olarak tahmin edilebilmektedir. Sınır testi modelleri, kısıtlanmamış hata düzeltme (unrestricted error correction) modellerinin en küçük kareler yöntemi ile tahmin edilmesine dayanmaktadır ve aşağ $1^{-}$ daki denklemlerde gösterilmektedir.

$$
\begin{aligned}
& \Delta \operatorname{lnCO}_{2}=a_{1}+a_{G D P} \operatorname{lnGDP}_{t-1}+a_{G D P^{2}} \operatorname{lnGDP}_{t-1}^{2}+a_{T R} \operatorname{lnTR}_{t-1}+ \\
& \sum_{i=1}^{p} a_{i} \Delta \operatorname{lnCO}_{2 t-i}+\sum_{j=0}^{q} a_{j} \Delta \operatorname{lnGDP}_{t-j}+\sum_{k=0}^{m} a_{k} \Delta \operatorname{lnGDP}_{t-k}^{2}+\sum_{r=0}^{n} a_{r} \Delta \operatorname{lnTR}{ }_{t-r}+\mu_{t} \\
& \Delta \operatorname{lnCO}_{2}=a_{1}+a_{G D P} \operatorname{lnGDP}_{t-1}+a_{G D P^{2}} \operatorname{lnGDP}_{t-1}^{2}+a_{G D P^{3}} \operatorname{lnGDP}_{t-1}^{3}+a_{T R} \operatorname{lnTR}_{t-1}+ \\
& \sum_{i=1}^{p} a_{i} \Delta \operatorname{lnCO}_{2 t-i}+\sum_{j=0}^{q} a_{j} \Delta \operatorname{lnGDP}_{t-j}+\sum_{k=0}^{m} a_{k} \Delta \operatorname{lnGDP}_{t-k}^{2}+\sum_{z=0}^{s} a_{z} \Delta \operatorname{lnGDP}_{t-z}^{3}+\sum_{r=0}^{n} a_{r} \Delta \ln T R_{t-r}+\mu_{t}
\end{aligned}
$$

Burada $\Delta$ değişkenlerin birinci farkını simgelemektedir. Yukarıdaki modellerde sinır testinin uygulanabilmesi için gecikme uzunluğunun belirlenmesi gerekmektedir. Gecikme uzunluğunun belirlenmesi için AIC (Akaike information criterion), SC (Schwarz information criterion) FPE (Final prediction error) ve HQ (Hannan-Quinn information criterion) gibi bilgi kriterlerinden yararlanılmaktadır. Ardından eş bütünleşme ilişkisi varlığının araştırılmasında bağımlı ve bağımsız değişkenlerin birinci dönem gecikmelerinin katsayılarına topluca $\mathrm{F}$ testi (wald test) uygulanarak anlamlılığının test edilmesi yoluyla belirlenmektedir. Değişkenler arasında eş bütünleşmenin olmadığını ifade eden H0 (sıfır) hipotezleri: 
$H_{0:}: a_{G D P}=a_{G D P^{2}}=a_{G D P^{3}}=a_{T R}=0 \quad$ Değişkenler arasında eş bütünleşmenin varlığını ifade eden alternatifhipotezler: $H_{A:}: a_{G D P} \neq a_{G D P^{2}} \neq a_{G D P^{3}} \neq a_{T R} \neq 0$ şeklinde oluşturulmaktadır. Bu amaçla, Pesaran ve Pesaran (1997) yada Pesaran vd. (2001) çeşitli anlamlllık seviyeleri için alt ve üst sınır değerlerinden oluşan kritik değerler seti türetmişlerdir. . Gözlem say1sının küçük olması durumunda, ilgili kritik değerler Pesaran vd. (2001) tarafından rapor edilen kritik değerlerden önemli ölçüde sapma gösterebilmektedir. Bu yüzden çalışmalarda 30-80 gözlem sayısına uygun olarak Narayan (2005) tarafından türetilen sinır testi için alt ve üst kritik değerler kullanılmaktadır. Alt sınır değeri, değişkenlerin tamamının $\mathrm{I}(0)$; üst sınır değeri ise, değişkenlerin tamamının I(1) olduğunu varsaymaktadır. Hesaplanan test istatistigi, üst s1nır kritik değerinden büyükse; incelenen değişkenler arasında eş bütünleşme ilişkisi olmadığını temsil eden yokluk hipotezi reddedilmektedir. Hesaplanan test istatistiği, alt sınır kritik değerinden küçükse; bu defa incelenen değişkenler arasında eş bütünleşme ilişkisi olmadığını temsil eden yokluk hipotezi kabul edilmektedir. Bu aşamada değişkenler arasında uzun dönemli bir ilişki yani eş bütünleşme olduğu kanıtlanırsa, bundan sonraki aşamada aşağıda denklem 5 ve 6 'da sirasıyla gösterilen uzun ve kısa dönem modelleri tahmin edilir.

$$
\begin{aligned}
& C O_{2 t}=\alpha_{2}+\sum_{i=1}^{a 2} \phi_{2 i} C O_{2 t-i}+\sum_{p=0}^{b 2} \beta_{2 p} G D P_{t-p}+\sum_{q=0}^{c 2} \varphi_{2 q} G D P_{t-q}^{2}+\sum_{r=0}^{d 2} \gamma_{2 r} G D P_{t-r}^{3}+\sum_{z=0}^{e 2} \delta_{2 z} T R_{t-z}+\varepsilon_{2 t} \\
& \Delta C O_{2 t}=\alpha_{3}+\sum_{i=1}^{a 3} \phi_{3 i} \Delta C O_{2 t-i}+\sum_{p=0}^{b 3} \beta_{3 p} \Delta G D P_{t-p}+\sum_{q=0}^{c 3} \varphi_{3 q} \Delta G D P_{t-q}^{2}+ \\
& \sum_{r=0}^{d 3} \gamma_{3 r} \Delta G D P_{t-r}^{3}+\sum_{z=0}^{e 3} \delta_{3 z} \Delta T R_{t-z}+\psi e c t_{t-1}+\varepsilon_{3 t}
\end{aligned}
$$

Burada $\psi, 7$ nolu denklemde nasıl hesaplandığı gösterilen ve uzun dönem dengeden sapmaların hangi hızla düzeldiğini gösteren hata düzeltme terimi (error correction term-ect) katsayısıdır.

$$
e c t_{t}=C O_{2 t}-\alpha_{2}-\sum_{i=1}^{a 2} \phi_{2 i} C O_{2 t-i}-\sum_{p=0}^{b 2} \beta_{2 p} G D P_{t-p}-\sum_{q=0}^{c 2} \varphi_{2 q} G D P_{t-q}^{2}-\sum_{r=0}^{d 2} \gamma_{2 r} G D P_{t-r}^{3}-\sum_{z=0}^{e 2} \delta_{2 z} T R_{t-z}
$$

Hata düzeltme terimi eksi işaretli olup istatiksel olarak anlamlı olmalıdır.

\section{Ampirik Sonuçlar}

Eş bütünleşme analizine geçmeden önce serilerin durağanlığının araştırılması gerekmektedir. Burada durağanlıktan kasıt, zaman serisinin ortalaması, varyansı ve kovaryansının zaman içerisinde değişmemesidir. Granger ve Newbold (1974), duragan olmayan zaman serileriyle çalışılması halinde değiş- kenler arasında sahte regresyon problemiyle karșilaşlabileceğini göstermişlerdir. Diğer taraftan ARDL sinır testinde serilerin maksimum birinci dereceden durağanlaşması gerekmektedir. Bu nedenle çalışmanın ampirik kısmında öncelikle ADF ve PP birim kök testleri sınaması yapılmış ve sonuçları aşağıdaki Tablo 2'de verilmiştir. 
Tablo 2. ADF ve KPSS Birim Kök Test Sonuçları

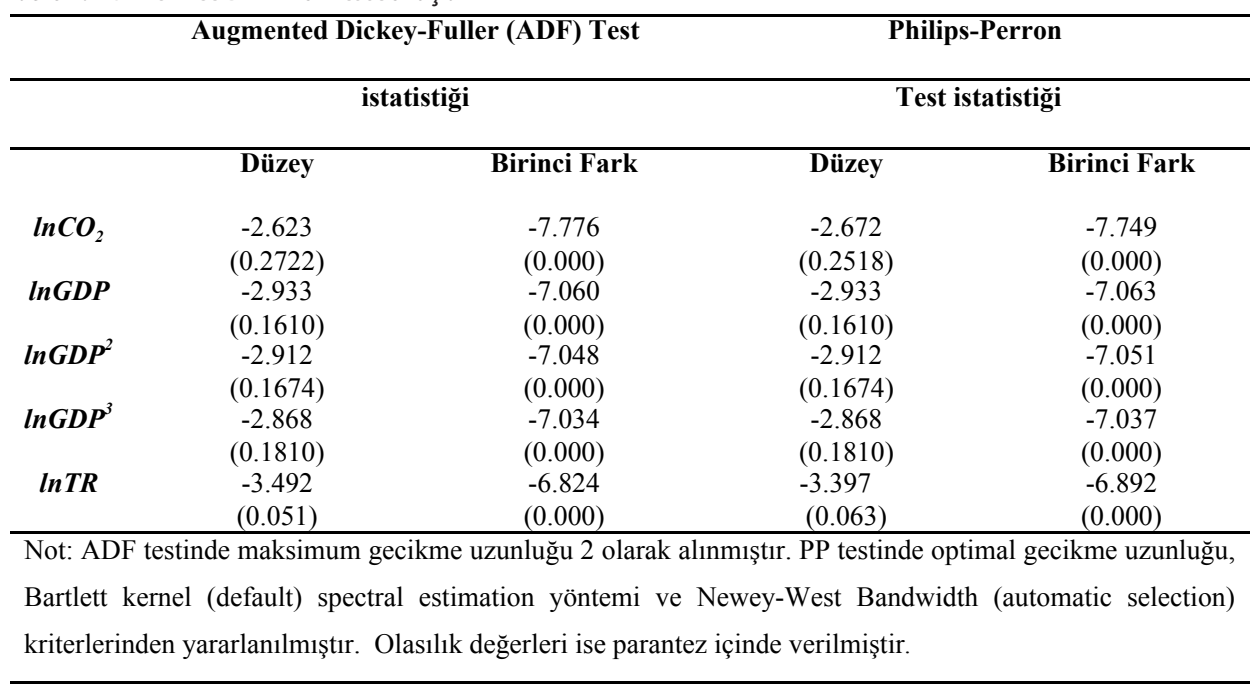

ADF ve PP birim kök test sonuçlarına bakıldığında her iki testte serilerin seviyede birim kök taşıdığı yönündeki $\mathrm{H} 0$ hipotezinin kabul edildiği görülmektedir. Diğer taraftan serilerin birinci farkı alındığında her iki test de $\mathrm{H} 0$ hipotezini reddetmektedirler. Dolayısıyla ARDL yöntemi için ön koşulun sağlandığ tespit edilmiş olup kubik ve kuadratik model için elde edilen ARDL eş bütünleşme analizi sonuçları aşağıda Tablo 3 ve Tablo 4'de gösterilmiştir. Son olarak tahmin edilen ARDL modelinin kararlılığını araştırmak başka bir ifadeyle değişkenlere ilişkin yapısal kırılmanın olup olmadığını belirlemek amacıyla kullanılan CUSUM (cumulative sum) ve CUSUMSQ (cumulative sum of squares) testlerinin sonuçları Tablo 3.1 ve Tablo 4.1'de gösterilmiştir. Eğer, CUSUM ve CUSUMSQ istatistikleri \%5 anlamlllık düzeyinde kritik sınırlar içerisinde (iki çizgi arasında) kalıyorsa, ARDL modelindeki katsayıların istikrarlı olduğunu ifade eden $\mathrm{H} 0$ hipotezi kabul edilecektir. (BahmaniOskooee, Ng, 2002, s. 25).

Tablo 3. ARDL Sınır Testi Sonuçları

\begin{tabular}{|c|c|c|}
\hline $\begin{array}{l}\text { Kubik Form } \\
\text { Eşbütünleşme Analizi }\end{array}$ & F-statistic & $\% 95$ alt sinır $-\% 95$ üst sinır \\
\hline $\begin{array}{l}C O 2 i t=\beta 0+\beta 1 G D P i t+\beta 2 G D P^{2} i t+\beta 3 G D P^{3} i t+ \\
\beta 4 T R i t+\operatorname{Eit}_{\text {ARDL }(1,0,0,0,0)}\end{array}$ & $5.8413^{* *}$ & $3.8008-5.0834$ \\
\hline Uzun Dönem & Katsayı & t-oranı[olasılık] \\
\hline LNGDP & $353.915^{* * *}$ & $2.7346[0.009]$ \\
\hline LNGDP $^{2}$ & $-22.359 * * *$ & $-2.6391[0.011]$ \\
\hline LNGDP $^{3}$ & $0.472 * * *$ & $2.5558[0.014]$ \\
\hline LNTRD & $0.140 * * *$ & $3.6589[0.001]$ \\
\hline Sabit terim & $-1864.7 * * *$ & $-2.8311[0.007]$ \\
\hline $\begin{array}{l}\text { Hata Düzeltme Modeli } \\
\Delta \text { LNGDP }\end{array}$ & $255.680 * * *$ & $2.7441[0.009]$ \\
\hline $\begin{array}{l}\Delta \text { LNGDP }^{2} \\
\Delta \text { LNGDP }^{3} \\
\Delta \text { LNTRD } \\
\text { ecm(-1) } \\
\text { Hata düzeltme katsayıs }\end{array}$ & $\begin{array}{r}-16.153 * * * \\
0.341 * * * \\
0.101 * * * \\
-0.722 * * *\end{array}$ & $\begin{array}{c}-2.6565[0.011] \\
2.5800[0.013] \\
4.3885[0.000] \\
-7.4409[0.000]\end{array}$ \\
\hline Diagnostic testler & İstistik [olasılık] & $\mathbf{R}^{2}$-Adjusted $\mathbf{R}^{2}$ \\
\hline Otokorelasyon-Breusch Godfrey LM testi & $3.1828[0.081]$ & $0.99663-0.9961$ \\
\hline Değişen Varyans Heteroscedisticity testi & $3.3144[0.075]$ & Dönüm Noktas1 \\
\hline Normallik-J国B Normality test, & $0.3824[0.826]$ & yok \\
\hline
\end{tabular}


Tablo 3.1. Kubik form için Cusum of Squares ve Cusum Testi

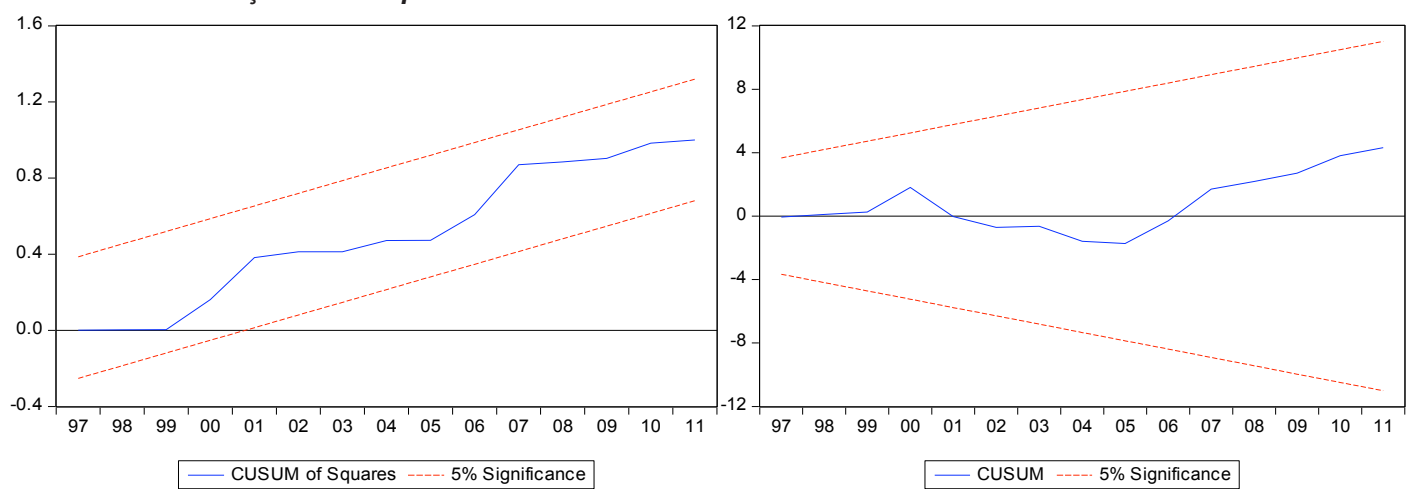

Tablo 4. ARDL Sınır Testi Sonuçları

\begin{tabular}{|c|c|c|}
\hline $\begin{array}{l}\text { Kuadratik Form } \\
\text { Eşbütünleşme Analizi }\end{array}$ & F-İstatistiği & $\% 95$ alt sınır -\%95üst sınır \\
\hline $\begin{array}{l}C O 2 i t=\beta 0+\beta 1 G D P i t+\beta 2 G D P^{2} i t+\beta 3 T R i t+\varepsilon i t \\
\text { ARDL }(1,0,0,0,)\end{array}$ & $6.6979 * *$ & $3.5000-4.6428$ \\
\hline $\begin{array}{l}\text { Uzun Dönem } \\
\text { LNGDP }\end{array}$ & $\begin{array}{c}\text { Katsayı } \\
21.374 * * *\end{array}$ & $\begin{array}{c}\text { t-oranı[olasılık] } \\
10.6742[0.000]\end{array}$ \\
\hline $\begin{array}{l}\text { LNGDP }^{2} \\
\text { LNTRD }\end{array}$ & $\begin{array}{r}-0.656^{* * * *} \\
0.085^{* * *}\end{array}$ & $\begin{array}{r}-10.1424[0.000] \\
3.3735[0.002]\end{array}$ \\
\hline Sabit terim & $-165.923 * * *$ & $-10.7310[0.000]$ \\
\hline \multicolumn{3}{|l|}{ Hata Düzeltme Modeli } \\
\hline $\begin{array}{l}\Delta \text { LNGDP }^{2} \\
\Delta \text { LNTRD } \\
\text { ecm(-1) } \\
\text { Hata düzeltme katsayısı }\end{array}$ & $\begin{array}{r}-0.480 * * * \\
0.062 * * * \\
-0.732 * * *\end{array}$ & $\begin{array}{r}5.1733[0.000] \\
3.5117[0.001] \\
-7.9027[0.000]\end{array}$ \\
\hline Diagnostic testler & İstistik [olasılık] & $\mathbf{R}^{2}$-Adjusted $\mathbf{R}^{2}$ \\
\hline $\begin{array}{l}\text { Otokorelasyon-Breusch Godfrey LM testi } \\
\text { Değişen Varyans-Heteroscedisticity testi } \\
\text { Normallik-J国B Normality test, }\end{array}$ & $\begin{array}{l}0.306[0.583] \\
0.134[0.715] \\
0.454[0.797]\end{array}$ & $\begin{array}{c}0.9957-0.9954 \\
\text { Dönüm Noktas1 } \\
11.277 \$\end{array}$ \\
\hline $\begin{array}{l}\text { Not: Maksimum gecikme uzunluğu } 2 \text { olarak a } \\
\text { belirlenmiştir. }{ }^{*}, * *, * * \text { sirasiyla } \% 10 \% 5 \text { ve }\end{array}$ & $\begin{array}{l}\text { gecikme uzunlukl } \\
\text { amlılığı ifade etmel }\end{array}$ & kaike bilgi kriterine göre \\
\hline
\end{tabular}

\section{Tablo 4.1. Kubadratik form için Cusum of Squares ve Cusum testi}

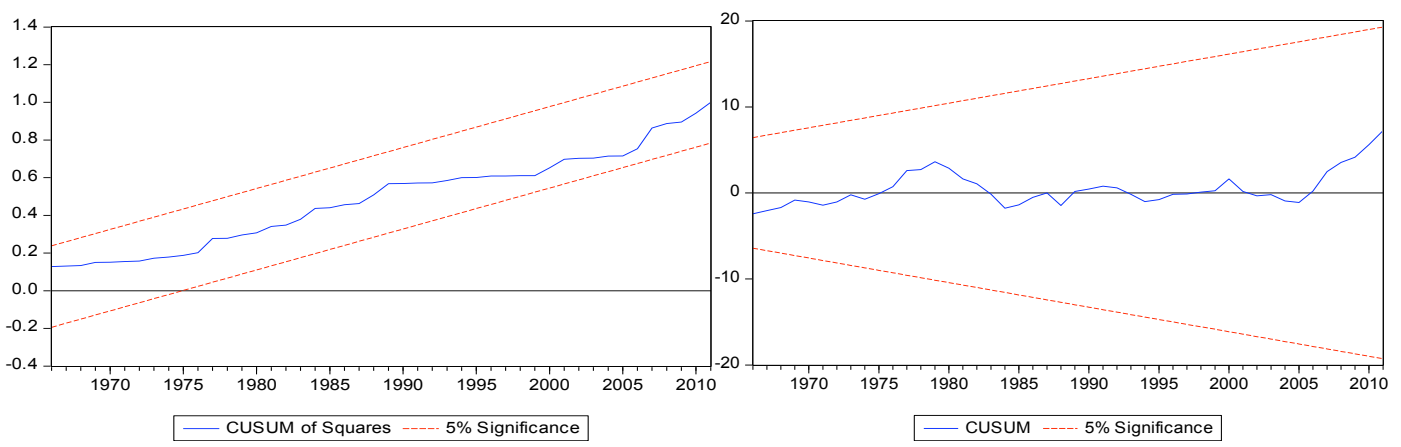


Çevre kirliliği ile ekonomik büyüme arasındaki ilişkiyi incelemek için kullanılan kubik model için bazı diagnostik testlerinden geçen ARDL sinır testi sonuçlarına bakıldığında değişkenler arasında uzun dönemli bir ilişki olduğu yönündeki hipotez kabul edilmektedir. Elde edilen uzun dönem katsayılarının hepsi anlamlı olup, gdp gdp ${ }^{2}$, gdp $^{3}$ nin sirasıyla çevre kirliliğini pozitif, negatif ve pozitif etkilediği ayrıca modelde kontrol değişkeni olarak kullanılan ticari açıklığında çevre kirliliğini pozitif etkilediği görülmektedir. Bu sonuçlar; çevre kirliliği ile ekonomik büyüme arasında $\mathrm{N}$ şeklinde bir ilişki olduğuna işaret etmektedir. Yine kubik model için elde edilen hata düzeltme katsayısının (-0.72) eksi işaretli olup anlamlı olduğu görülmektedir. Buna göre değişkenler arasındaki uzun dönemli dengeden sapmanın yaklaşık olarak bir buçuk dönem sonra tekrar sağlanacağ söylenebilir. Değişkenlerde yapısal kırılmanın olup olmadığını araştırdığımız Cusum of Squares ve Cusum testi sonuçlarına bakıldığında modelde yer alan değişkenlerde 1960-2011 dönemleri arasında herhangi bir yapısal kırılma olmadığ bul edilmektedir. Diğer taraftan yine çevre kirliliği ile ekonomik büyüme arasındaki ilişkiyi incelemek için kullanılan kuadratik model için bazı diagnostik testlerinden geçen ARDL sınır testi sonuçlarına bakıldığında, değişkenler arasında uzun dönemli bir ilişki olduğu yönündeki hipotez kabul edilmektedir. Elde edilen uzun dönem katsayılarının hepsi anlamlı olup, gdp gdp ${ }^{2}$ nin sırasıyla çevre kirliliğini pozitif ve negatif etkilediği ayrıca modelde kontrol değişkeni olarak kullanılan ticari açıklığında çevre kirliliğini pozitif etkilediği görülmektedir. Bu sonuçlar, çevre kirliliği ile ekonomik büyüme arasında ters $U$ şeklinde bir ilişki olduğuna işaret etmektedir. Yine kuadratik model için elde edilen hata düzeltme katsayısının (-0.73) eksi işaretli olup anlamlı olduğu görülmektedir.

\section{Sonuç ve Öneriler}

Ekonomik büyüme ve çevre ilişkisini irdelemeyi amaçlayan bu çalışmada, bu ilişkinin teorik altyapısı gözden geçirilmiş ve bu teorik altyapı ampirik olarak kanıtlanmaya çalışılmıştır. 1970'li yılların başlarında özellikle Stocholm Konferansı ile birlikte gündeme gelen çevre olaylarını takiben bu ilişki farklı yönleriyle farklı disiplinler tarafından ele alınmıştır. Bunun sebebi, çevrenin canlılar için hayati önem taşıması ve çevrenin ciddi problemlerle karşı karşıya kalmasıdır.
$\mathrm{Bu}$ problemlerin başında, alıcı ortamlarının kirlilik özümseme kapasitelerinin aşılmaya başlanması, doğal ortamdaki dengelerin geri dönüşü, zor/imkansız bir şekilde değişiyor olması, çevre kirliliği kaynaklı büyük ölçekli sağlık sorunlarının gündeme gelmesi, doğal kaynakların hızla tüketilmesi, küresel ısınma ve iklim değişikliği ve bunun bir sonucu olan Türkiyede de son zamanlarda sıklıkla karşılaşılan sel felaketleri, biyolojik çeşitliliğin azalması, hava kirliliği ve toprak kirliliği vb. süreçler gelmektedir. Bu çalışmada iktisadi disiplin altında bu konuya ele alan ve neredeyse tüm çalışmaların bu hipotez etrafında toplandığı Çevresel Kuznet Eğrisi Hiptezi'nin geçerliliğini sınamaya yönelik çalışılmıştır. ÇKE hipotezi kısaca gelir artışının belli bir eşiğe kadar çevre kirliliğini artıracağı, bu eşik noktasından sonra hem temiz çevre talebi hem de yapısal ve teknolojik etkiden dolayı çevresel kirliliği azaltacağını ileri sürer. ÇKE geçerliliği durumunda ekonomik büyüme, çevresel kirliliğin hem nedeni hem de çözümüdür. Bu yaklaşım genellikle çevresel kirliliği azaltmak amacıyla ekonomik büyüme politikalarından taviz verilmemesi gerektiğini ileri sürer. ÇKE geçerli olmadığı durumlarda ise ekonomik büyüme yani üretim artışı çevresel kirliliğin sadece nedenidir. Bunun sonucunda da Neo-Klasik büyüme anlayışının yerine geçecek arayışlar hızlanmıştır. Özellikle Rio de Janerioda UNCED konferansında vurgulanan kazan kazan (win-win) anlayışına uygun ekolojik paradigmayı da dikkate alan anlayış son dönemlerde önem kazanmıştır. Bu nedenle; ÇKE’nin geçerli olup olmadığı ülkelerin uygulayacağı ekonomik büyüme politikaları bakımından önemli bir sorudur. Bu çalışmada, bu sorunun cevabı bulunmaya çalışılmıştır.

Bu amaçla çalışmada, 1960-2011 dönemi için ÇKE'nin Türkiye’de geçerliliği sınanmıştır. Öncelikle çevre kirliliği ile büyüme arasında uzun dönemli bir ilişki olup olmadığını araştırmadan önce serilerin durağanlığı Dickey ve Fuller (1981) tarafından geliştirilen ADF (Augmented Dickey-Fuller) ve Phillips ve Perron (1988) tarafından geliştirilen PP birim kök testleri araştırılmıştır. Bunun sonucunda çalışmada kullanılan tüm serilerin seviyede birim kök taşıdığı, birinci farkları alındığında ise durağanlaştığı tespit edilmiştir. Sonraki aşamada durağan olmayan seriler arasında durağan bir ilişkinin yani uzun dönemli bir ilişkinin olup olmadığı Pesaran (1997), Pesaran vd. (2000, 2001) tarafından geliştirilen ARDL modeli ile araştırılmıştır. Elde edilen bulgular hem kuadra- 
tik hemde kubik model için uzun dönemli bir ilişki olduğu yönündedir. Kuadratik model için elde edilen uzun dönemli katsayılara bakıldığında, gdp ve gdp2'nin sırasılyla çevre kirliliğini pozitif ve negatif etkilediği ayrıca modelde kontrol değişkeni olarak kullanılan ticari açıklığında çevre kirliliğini pozitif etkilediği görülmektedir. Bu sonuç değişkenler arasında ters U şeklinde bir ilişki olduğunu yani ÇKE’nin ilgili dönemde Türkiye'de geçerli olduğunu desteklemektedir. Bunun anlamı Türkiyede kişi başına gelir arttıkça başlangıçta çevresel kirlilik artacak, kişi başına gelir belli eşik değerine ulaştığında ise çevresel kirlilik azalmaya başlayacaktır. Bu eşik değeri yani dönüm noktası çalışmada 11.277 \$ olarak hesaplanmıştır. Türkiye'de kişi başına gelir henüz bu seviyeye ulaşmamak ile birlikte ekonomik büyümenin devamında bu gelir seviyesine ulaşılması ile birlikte çevresel kirliliğin azalmaya başlayacağı söylenebilir. $\mathrm{Bu}$ sonuç; ekonomik gelişmeyi tek yönlü bir tehdit olarak görmek yerine, kalkınma ile birlikte büyümenin getireceği baskıyı hafifletecek diğer mekanizmaları devreye sokacak çok yönlü bir süreç olarak kabul etmektedir. Bu mekanizmaların ise kurumsallaşma, teknoloji ve bilgi seviyesindeki değişmeler olduğu vurgulanmıştır. Kubik model için elde edilen uzun dönemli katsayılara bakıldığında gdp gdp2, gdp3’nin sırasıyla çevre kirliliğini pozitif, negatif ve pozitif etkilediği ayrıca modelde kontrol değişkeni olarak kullanılan ticari açıklığında çevre kirliliğini pozitif etkilediği görülmektedir. Bu sonuçlar çevre kirliliği ile ekonomik büyüme arasında $\mathrm{N}$ şeklinde bir ilişki olduğuna işaret etmektedir. Bu durumda kişi başına gelirin artması başlangıçta çevresel kirliliği artıracak, kişi başına gelir artışının devamında çevresel kirlilik azalsa da daha sonra tekrar artmaya başlayacaktır. $\mathrm{N}$ şeklinde bir ilișki bulunması durumunda fonksiyonda iki dönüm noktası olması gerekir. Bu dönüm noktalarının bulunamaması durumunda ise bulunan eğrinin sürekli artan bir ilişkinin trendini gösterebileceği çalışmada belirtilmişti. Çalışmada, bu dönüm noktaları tespit edilemediğinden kubik model için elde edilen sonucun $\mathrm{N}$ şeklinde bir ilişkinin varlığından çok sürekli artan bir ilişkinin trendini gösterdiği söylenebilir. Bu sonuca göre; kişi başına gelirdeki artış sürekli olarak çevre kirliliğini arttırmaktadır. Çalışmada elde edilen bulgular birlikte değerlendirildiğinde çevresel kirliliği azaltmak için kişi başına gelir artışı ile birlikte çevreye öncelik veren ekonomi politikalarının da yürürlüğe konulması gerekliliği ön plana çımaktadır. Bunun yanında uygulanacak po- litikalar AR-GE faaliyetlerine önem veren, bilgi üretmenin ve kullanmanın değerini arttıracak kurumsallaşmayı ön plana çıkaracak yönde olmalıdır. Aynı zamanda çevre bilinci artırılmalı ve yarının doğasının bugünden yaratılacağı gerçeği unutulmamalıdır.

\section{Kaynakça}

Akbostanc1, E., Türüt, A. S., Tunç, G. İ. (2009). The Relationship Between Income and Environment in Turkey: Is there An Environmental Kuznets Curve?. Energy Policy, 37, 861-867.

Atıcı, C., Kurt, F. (2007). Türkiye’nin Dış Ticareti ve Çevre Kirliliği: Çevresel Kuznets Eğrisi Yaklaşımı. Tarım Ekonomisi, 13(2), 61 - 69.

Aslan, F. (2010). İktisadi Büyümenin Sınırları ve Kalkınmanın Sürüdürülebilirliği. (Yayınlamış Yüksek Lisans Tezi), Ankara Üniversitesi/ Sosyal Bilimler Enstitüsü, Ankara

BahmanI-Oskooee, M., Raymond, C.W.N.G. (2002). Longrun Demand for Money in Hong Kong: An Application of The ARDL Model. International Journal of Business and Economics, 1(2), 147-155.

Başar, S., Temurlenk, M.S. (2007). Çevreye Uyarlanmış Kuznet Eğrisi: Türkiye Üzerine Bir Uygulama. İktisadi ve İdari Bilimler Dergisi, 21(1) 1-12.

Brown, R.L., James, D., Jonathan, M.E. (1975). Techniques for Testing the Constancy of Regression Relationships over Time. Journal of the Royal Statistical Society, 37(2),149-192.

Bölük, G., Mert, M. (2015). The Renewable Energy, Growth and Environmental Kuznets Curve in Turkey: An ARDL Approach. Renewable and Sustainable Energy Reviews, 52, 587-595.

Çiftlikli, M. (2011). Çevre Kirliliğinin Ekonomik Boyutları. Çevre Dergisi, 7, 46-48.

Dam, M.M., Karakaya, E., Bulut, Ş. (2013). Çevresel Kuznets Eğrisi ve Türkiye :Ampirik Bir Analiz. Dumlupinar Üniversitesi Sosyal Bilimler Dergisi, EYİ 2013 Özel Sayısı, 85-96. 
Dickey, D., Fuller, W.A. (1981). Likelihood Ratio Statistics for Autoregressive Time Series with a Unit Root, Econometrica, 49, 1057-72.

Erdem, E., Ulucak, R. (2012). Çevre İktisat İlişkisi ve Türkiye'de Çevre Politikalarının Etkinliği. Akademik Araştırmalar ve Çalı̧malar Dergisi, 6, 78-98.

Erdoğan, İ., Türköz, K., Görüş, M.Ş. (2015). Çevresel Kuznets Eğrisi Hipotezinin Türkiye Ekonomisi İçin Geçerliliği. Dumlupınar Üniversitesi Sosyal Bilimler Dergisi, 44, 113-123.

Engle, R.F., Granger, C.W.J. (1987). Cointegration and Error Correction: Representation, Estimation and Testing. Econometrica, 55, 251-76.

Granger, C.W.J., Newbold, P. (1974). Spurios Regressions in Econometrics. Journal of Econometrics, 2, 111-120.

Grossman, G.M., Alan, B.K. (1991). Environmental Impacts of a North American Free Trade Agreement. National Bureau of Economics Research Working Paper, No. 3194, NBER, Cambridge.

Johansen, S., Juselius, K. (1990). Maximum Likelihood Estimation and Inference on Cointegration - with Applications to The Demand for Money. Oxford Bulletin of Economics and Statistics, 52, 169-210.

Johansen, S. (1988). Statistical Analysis of Cointegration Vectors. Journal of Economic Dynamics and Control, 12, 231-254.

Koçak, E. (2014). Türkiye’de Çevresel Kuznets Eğrisi Hipotezinin Geçerliliği: ARDL Sınır Testi Yaklaşım. İsletme ve İktisat Çalıșmaları Dergisi, 3, 62-73.

Kuznets, S. (1955). Economic Growth and Income Inequality. American Economic Review, 45(1), 1-28.

Martin, L.C. (2002). The Environmental Kuznets Curve - A Survey of The Empirical Evidence and of Possible Causes. Discussion Paper Series No:390, Switzerland.
Narayan, P.K., (2005). The Savings and Investment Nexus for China: Evidence from Cointegration Test. Applied Economics, 91, 1979-1990.

Pesaran, M.H., Shin, Y., Smith, R.J. (2001). Bounds Testing Approaches to The Analysis of Level Relationships. Journal of Applied Econometrics, 16, 289 $-326$.

Pesaran, M.H., Shin, Y. (1999). An Autoregressive Distributed Lag Modeling Approach to Cointegration Analysis. The Ragnar Frisch Centennial Symposium. Ch. 11. Cambridge: Cambridge University Press.

Pesaran, M.H., Shin, Y., Smith, R.J. (2000), Structural Analysis of Vector Error Correction Models with Exogenous I(1) Variables. Journal of Econometrics, 97, 293-343.

Phillips, P.C.B., Perron, P. (1988). Testing for A Unit Root in Time Series Regression, Biometrika, 75, 335-346.

Saatci, M., Dumrul, Y. (2012). The Relationship Between Economic Growth and Environmental Pollution: The Estimation of Environmental Kuznets Curve with A Cointegration Analysis of Structural Breaks for Turkish Economy. Erciyes University, Journal of the Faculty of Economics and Administrative Sciences, 37,65-86.

Soytaş, U., Sarı, R. (2009). Energy Consumption, Economic Growth, and Carbon Emissions: Challenges Faced by an EU Candidate Member. Ecological Economics, 68, 1667-1675.

Şahinöz, A., Fotourehchi, Z. (2013). Çevresel Kuznet Eğrisi: İndirgenmiş ve Ayrıştırılmış Modellerle Ampirik Bir Analiz. H.Ü. İktisadi ve İdari Bilimler Fakültesi Dergisi, 31 (1), 199-224.

Tutulmaz, O. (2011). Ekonomi- Çevre İlişkisi ve Sürüdülebilir Kalkınma : Ampirik Bir Değerlendirme. (Yayınlanmış Doktora Tezi), Hacettepe Üniversitesi/ Sosyal Bilimler Enstitüsü, Ankara. 